\title{
Desenvolvimento de mudas de Schizolobium amazonicum Huber ex Ducke em diferentes ambientes em viveiro ${ }^{1}$
}

\author{
Taciana Frigotto ${ }^{2}$; Eleandro José Brun ${ }^{3}$; Carlos Cesar Mezzalira ${ }^{4}$ : Marcio Carlos Navroski ${ }^{5}$; Suzamara \\ Biz $^{6}$; Raquel Rossi Ribeiro ${ }^{7}$
}

Resumo: O objetivo do estudo foi avaliar o desenvolvimento de mudas de Schizolobium amazonicum sob o efeito de diferentes ambientes de viveiro, nos seguintes tratamentos: T1- mudas a pleno sol, T2 - mudas em casa de sombra (75\%) e T3 - Casa de vegetação. As variáveis analisadas foram: índice de sobrevivência, altura da parte aérea (h), diâmetro do colo (dc) e número de folhas (nf). O crescimento em altura foi maior na casa de vegetação $(50,3 \mathrm{~cm})$, semelhante na casa de sombra $(49,0 \mathrm{~cm})$ e inferior nas mudas a céu aberto $(46,2 \mathrm{~cm})$. Quanto ao diâmetro de colo, as mudas da casa de vegetação tiveram crescimento maior $(6,6 \mathrm{~mm})$, semelhante na casa de sombra $(6,3 \mathrm{~mm})$, e superiores a céu aberto, com o menor crescimento $(5,2 \mathrm{~mm})$. O número de folhas na casa de vegetação apresentou os melhores resultados $(3,9)$, seguidos pela casa de sombra $(3,5)$, os quais foram superiores ao tratamento a céu aberto $(0,3)$. Conclui-se que as mudas de paricá podem ser produzidas em casa de vegetação ou em casa de sombra, porém não a céu aberto, devido aos danos do frio às mudas.

Palavras - chave: Produção de mudas; Paricá; Aclimatação.

\section{Development of seedlings Schizolobium amazonicum Huber ex Ducke in different environments in nursery}

\begin{abstract}
This study aimed to evaluate the development of seedlings Schizolobium amazonicum under the effect of different environments nursery, the following treatments: T1 - seedlings in the open area, T2 - seedlings in shade house (75\%) and T3 - green house. The variables analyzed were: survival rate, height of shoots (h), stem diameter (dc) and leaf number (nf). Seedling growth in height was greater in the greenhouse $(50.3 \mathrm{~cm})$, similar in shade house $(49.0 \mathrm{~cm})$ and lower in the seedlings in the open area $(46.2 \mathrm{~cm})$. For the stem diameter, seedlings of greenhouse had higher growth $(6.6 \mathrm{~mm})$, similar in shade house $(6.3 \mathrm{~mm})$, and higher in the open area, with the lowest growth $(5.2 \mathrm{~mm})$. The number of leaves in the greenhouse showed the best results (3.9), followed by shade house (3.5), which were higher than the open treatment $(0,3)$. We conclude that the parica seedlings can be produced in a greenhouse or shade house, but not in the open due to damage from the cold to the seedlings.
\end{abstract}

Keywords: Plant propagation; Parica; Acclimatization.

\footnotetext{
${ }^{1}$ Recebido em 25.02.2015 e aceito para publicação como artigo científico em 06.07.2015.

${ }^{2}$ Engenheira Florestal, Mestranda do Programa de Pós-graduação em Engenharia Florestal do Centro de Ciências Agroveterinárias da Universidade do Estado de Santa Catarina (CAV-UDESC). E-mail: <tacianafrigotto@ gmail.com>.

${ }^{3}$ Engenheiro Florestal, Dr., Professor da Universidade Tecnológica Federal do Paraná - Câmpus Dois Vizinhos.

${ }^{4}$ Engenheiro Florestal formado pela Universidade Tecnológica Federal do Paraná - Câmpus Dois Vizinhos.

${ }^{5}$ Engenheiro Florestal Dr., Professor do Centro de Ciências Agroveterinárias (CAV-UDESC).

${ }^{6}$ Engenheira Florestal, Mestranda do Programa de Pós-graduação em Agronomia da UNICENTRO Campus Guarapuava.

${ }^{7}$ Engenheira Florestal, Mestranda do Programa de Pós-graduação em Agronomia da UTFPR Campus Pato Branco.
} 


\section{Introdução}

O paricá (Schizolobium amazonicum) é uma espécie da família Caesalpinaceae. No Brasil, é encontrado nos estados do Amazonas, Pará, Mato Grosso e Rondônia, em solos argilosos de florestas primárias e secundárias, tanto em terra firme quanto em várzea alta, ocorre em altitudes de até $800 \mathrm{~m}$. A emergência ocorre de 6 a 45 dias após a semeadura. O poder germinativo depende da eficácia do tratamento de superação de dormência, podendo proporcionar percentagens de germinação superiores a 85\% (SOUZA et al., 2005).

Sua madeira é considerada leve $\left(0,30 \mathrm{~g} \mathrm{~cm}^{-3}\right)$, possuindo cor branca, com indicações de uso para lâminas médias ou miolos de compensados, brinquedos, caixotaria leve, portas, entre outros (CARVALHO, 2007). Apresenta processamento fácil e recebe bom acabamento, mas possui baixa durabilidade natural. A espécie pode ser utilizada na arborização urbana, em praças e jardins. Por apresentar rápido crescimento e bom desempenho em formações homogêneas e em consórcios, também é indicada para plantios comerciais, sistemas agroflorestais e reflorestamento de áreas degradadas (SOUZA et al., 2005).

Com o aumento da área implantada com sistemas agroflorestais nos últimos anos, principalmente na Região Amazônica e visando a preservação da floresta nativa e o uso racional do solo, o paricá tem se tornado uma importante alternativa para estes sistemas (PECK, 1979). O mesmo autor incluiu o paricá na seleção de espécies leguminosas para consórcios agroflorestais. Concomitantemente ao autor citado acima, Costa et al. (1998) destacaram o bom desenvolvimento da espécie em plantios homogêneos ou consorciados, evidenciando o seu potencial para plantios em áreas degradadas, reflorestamentos e sistemas agroflorestais na região amazônica.

Para a expansão do cultivo, é fundamental o estudo da influência de fatores como densidade de plantio, água e luz para o desenvolvimento de tecnologia de produção de mudas com alto padrão de qualidade (UCHIDA e CAMPOS,
2000). Dessa forma a produção de mudas em viveiros constitui uma das fases mais importantes do processo de implantação de povoamentos florestais, pois estas podem comprometer todas as operações seguintes (COSTA et al., 2008).

Conforme relatado em trabalhos no norte do Brasil, a espécie possui um alto potencial de crescimento e tem inúmeras possibilidades de uso, isto justifica a necessidade de estudos dirigidos à espécie. Desta forma, o presente trabalho teve por objetivo avaliar a adaptação de mudas Schizolobium amazonicum no Sudoeste do Paraná sob influência de diferentes condições de ambiente de viveiro.

\section{Material e métodos}

O estudo foi realizado na Unidade de Ensino e Pesquisa (UNEPE) de Silvicultura da Universidade Tecnológica Federal do Paraná (UTFPR), Campus Dois Vizinhos. O clima característico da região é o $\mathrm{Cfa}$, subtropical com chuvas bem distribuídas durante o ano e verões quentes (ALVARES et al., 2013). A região registra temperaturas médias anuais de $19{ }^{\circ} \mathrm{C}$ e pluviosidade média de $2025 \mathrm{~mm}$ anuais (IAPAR, 2008). As sementes de Schizolobium amazonicum utilizadas no estudo são oriundas de matrizes selecionadas, da região de Alta Floresta, norte do Mato Grosso. Para superar a dormência, foi utilizado o método de escarificação mecânica com lixamento na parte oposta a micrópila. Em seguida, efetuou-se a semeadura direta das mesmas em sacos de polietileno $(12 \times 5 \mathrm{~cm})$, contendo substrato compostos por: terra de subsolo $(50 \%)$, areia lavada $(25 \%)$ e cama de aviário $(25 \%)$. Foram semeados 150 sacos com duas sementes cada. Os sacos de polietileno, com capacidade para dois litros de substrato, foram dispostos em canteiros sob telas de sombrite, de cor preta, com $75 \%$ de sombreamento.

Após o plantio, as embalagens contendo as sementes receberam três irrigações diárias até o umedecimento completo do solo. Quando as mudas completaram seis meses de idade, as 
mesmas foram separadas em diferentes ambientes, em 5 repetições com 5 plantas cada, sendo colocadas em canteiro a pleno sol (T1), casa de sombra (75\% de sombreamento) (T2) e casa de vegetação (T3), ambas contendo sistema de irrigação com acionamento manual, realizado três vezes ao dia e irrigado até próximo a capacidade de campo do substrato. $\mathrm{O}$ estudo foi conduzido entre os meses de junho a setembro de 2009.

As variáveis analisadas durante 0 desenvolvimento, a cada 25 dias, foram: altura da parte aérea $(\mathrm{h})$ determinada utilizando uma régua, sendo medida do colo da muda até a ponta da última folha; o diâmetro do colo (dac) medido com o auxílio de um paquímetro digital, ao nível do substrato e o número de folhas (nf), onde contou-se todas as folhas desenvolvidas em cada muda.

As variâncias dos tratamentos foram testadas quanto à homogeneidade pelo teste de Bartlett. Após verificação da homogeneidade das variâncias os dados foram submetidos à análise de variância e quando houve diferença significativa na análise de variância, houve aplicação de regressão polinomial ou teste de médias. Os tratamentos de localização das mudas foram analisados pelo teste de médias de Tukey e os tempos de avaliação por meio de regressão polinomial, ambos ao nível de $5 \%$ de probabilidade de erro. A análise dos dados foi realizada no pacote estatístico SISVAR 5.3 e os gráficos desenvolvidos em Microsoft Excel.

\section{Resultados e Discussão}

Segundo Paiva e Gomes (1993), várias são as características utilizadas na avaliação da qualidade de mudas de espécies florestais e dentre eles destacam-se a altura da parte aérea, a conformação do sistema radicular, o diâmetro do coleto, a proporção entre as partes aérea e radicular, entre outros. Entretanto, não se recomenda a avaliação isolada desses fatores, pois como exemplo, mudas com maior altura podem apresentar balanço desfavorável entre a parte radicular e aérea e vir a causar tombamento das mesmas à campo (GURTH, 1976).

$\mathrm{Na}$ avaliação das características morfológicas das mudas de Paricá aos 280 dias, observou-se diferença significativa entre os tratamentos para todas as variáveis (Tabela 1). As mudas, na casa de vegetação, apresentaram os melhores resultados para todas as variáveis, entretanto, não diferiram estatisticamente das mudas em casa de sombra.

$\mathrm{Na}$ casa de vegetação, o crescimento em altura das mudas foi aproximadamente $6 \mathrm{~cm}$ maior em relação a área a céu aberto, além de apresentar um ganho de $0,72 \mathrm{~cm}$ no diâmetro de colo e duas folhas a mais. Esses ganhos em relação a estas características representam redução no tempo de permanência das mudas no viveiro e minimização dos custos de produção.

Tabela 1: Desenvolvimento de mudas de Schizolobium amazonicum aos aos 280 dias.

Table 1: Development seedlings Schizolobium amazonicum to 280 days.

\begin{tabular}{ccccc}
\hline Tratamento & Altura $(\mathbf{m})$ & DAC $(\mathbf{m m})$ & $\mathbf{N}^{\mathbf{0}}$ de folhas & Sobrevivência (\%) \\
\hline Pleno Sol & $44,47 \mathrm{~b}^{*}$ & $6,41 \mathrm{~b}$ & $1,33 \mathrm{~b}$ & $42 \mathrm{~b}$ \\
Casa de sombra $(75 \%)$ & $49,04 \mathrm{a}$ & $7,12 \mathrm{a}$ & $3,02 \mathrm{a}$ & $88 \mathrm{a}$ \\
Casa de vegetação & $50,29 \mathrm{a}$ & $7,13 \mathrm{a}$ & $3,25 \mathrm{a}$ & $92 \mathrm{a}$ \\
\hline
\end{tabular}

*Médias seguidas pela mesma letra na coluna, não diferem entre si pelo teste de Tukey a $5 \%$ de probabilidade de erro.

O tratamento a pleno sol apresentou os menores valores para todas as variáveis. Este fato pode estar relacionado à baixa tolerância da espécie ao frio, pois em junho as temperaturas foram menores em relação a agosto e setembro, ou seja, ocorreram variações na escala de três a cinco graus de temperatura, além da ocorrência de geada. Observamos então um melhor 
desenvolvimento das mudas em ambientes mais sombreados (casa de sombra e casa de vegetação), concluindo que o sombreamento tem efeito positivo sobre as plantas de paricá.

Ao final das avaliações, aos 280 dias, podese verificar um aumento de cerca de $8 \mathrm{~cm}$ em altura, confirmando que a espécie se desenvolveu bem durante o período, especialmente nos ambientes mais sombreados, alcançando aproximadamente $50 \mathrm{~cm}$ ao final dos 280 dias de viveiro (Figura 1). Observou-se o maior crescimento do paricá $(50,29 \mathrm{~cm}$ e 49,04 $\mathrm{cm})$ na casa de vegetação e de sombra a $75 \%$ respectivamente, ou seja, no maior índice de sombreamento.

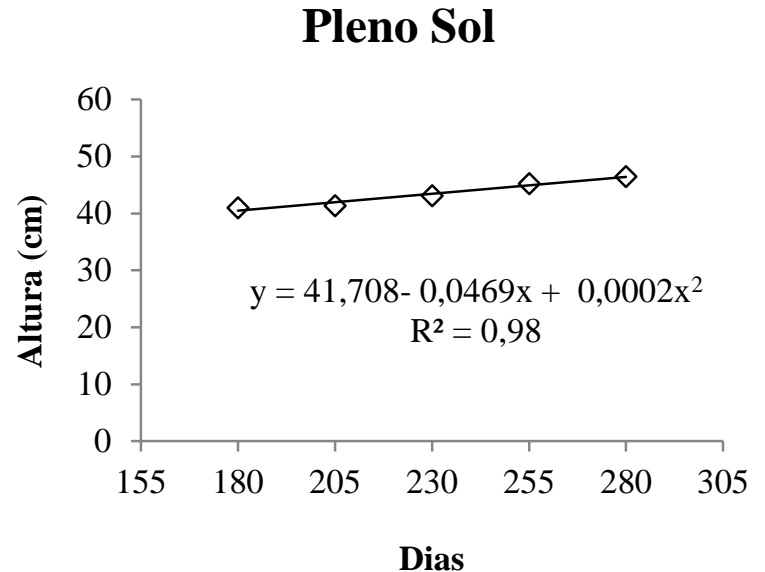

Dias

\section{Sombrite}

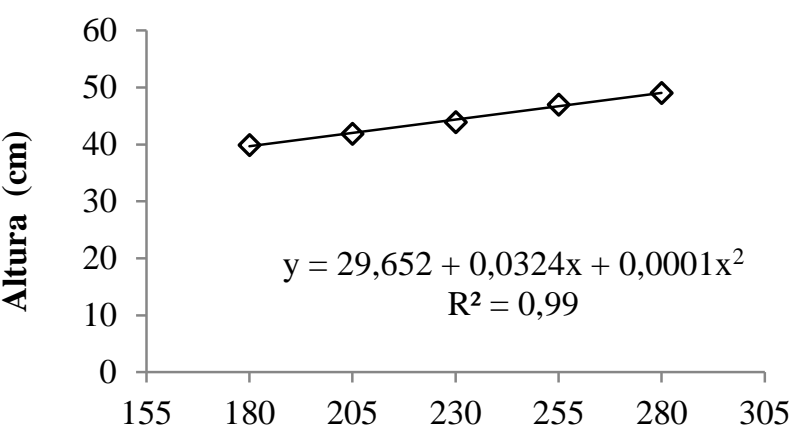

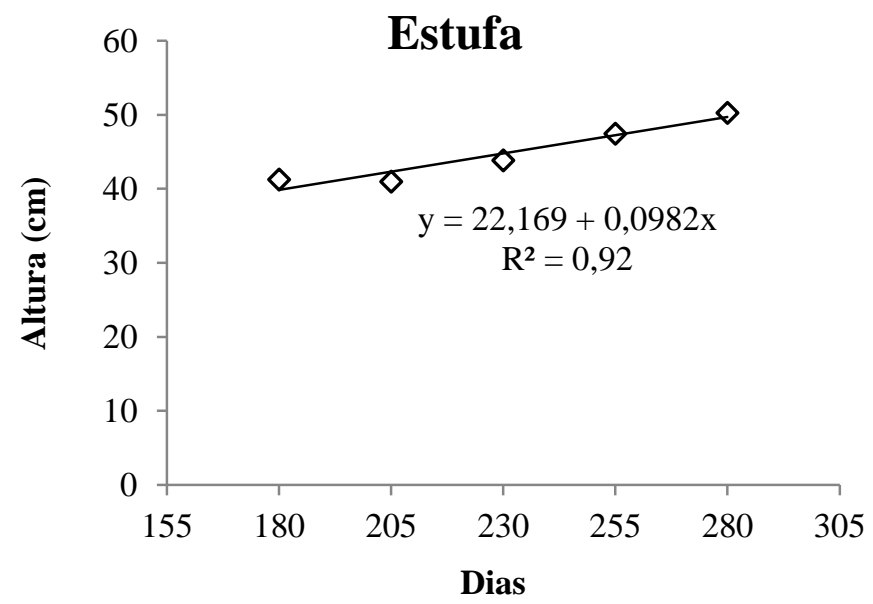

Figura 1: Altura $(\mathrm{cm})$ das mudas de Schizolobium amazonicum em diferentes idades de avaliação na média dos três ambientes. Figure 1: Height $(\mathrm{cm})$ of Schizolobium amazonicum seedlings at different ages on the evaluation average of three environments

O mesmo resultado, de maior desenvolvimento inicial das plantas em ambientes mais sombreados foi constatado por Rosa et al. (2009), onde as plantas avaliadas obtiveram maior crescimento em altura $(22,8 \mathrm{~cm}$ após 60 dias de avaliação) em sombreamento de $70 \%$. No entanto, Vieira et al. (2008), estudando o melhor ambiente (pleno sol, sol direto por meio dia, casa de vegetação com $50 \%$ de sombra) em viveiro, para o desenvolvimento de mudas de Schizolobium parahyba, observaram um aumento significativo $(40 \mathrm{~cm})$ na altura no final da avaliação, aos 120 dias, independente do ambiente a qual as mudas foram destinadas.

Assim, Melo e Cunha (2008) consideram que a altura da parte aérea apresenta comportamento inversamente proporcional aos níveis de luminosidade recebidos pelas plantas, e o rápido desenvolvimento obtido pelas mudas sombreadas deve se à busca de luminosidade 
pelas plantas.

Em relação ao diâmetro do colo, desde a primeira avaliação, foram percebidas poucas

\section{Pleno Sol}

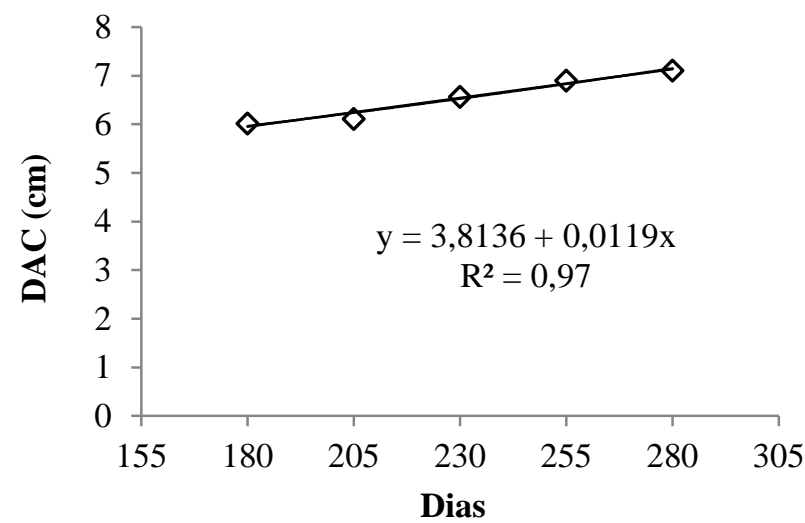

diferenças nos valores no decorrer das demais avaliações (Figura 2).

\section{Sombrite}

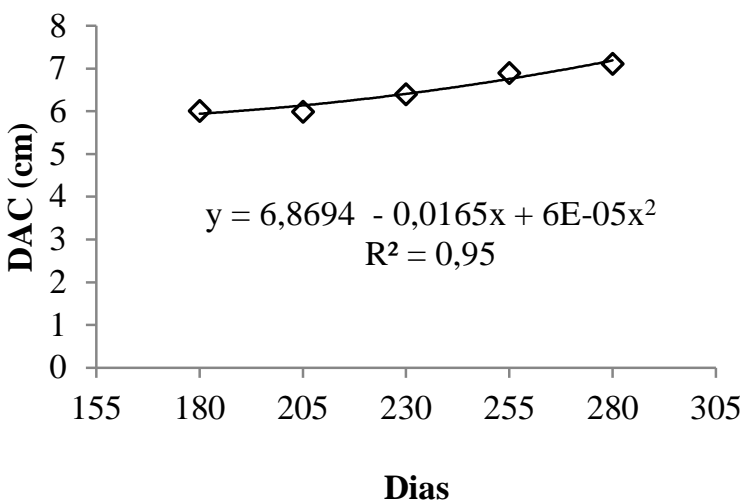

\section{Estufa}

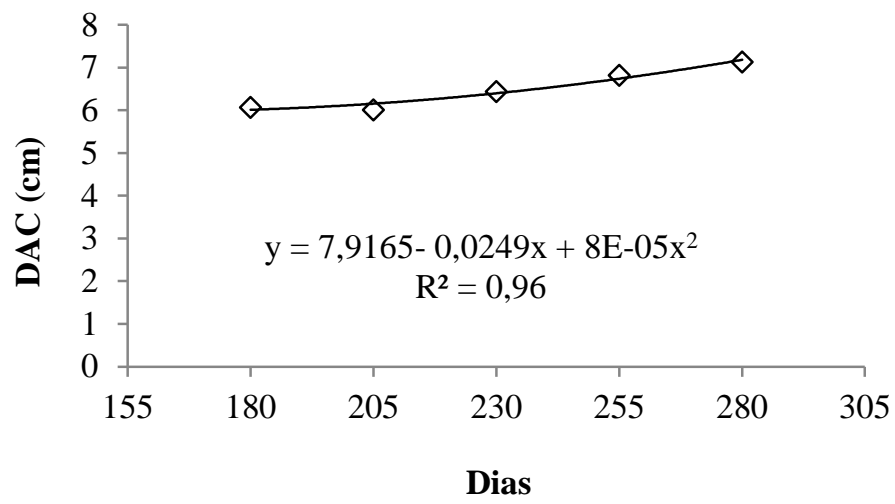

Figura 2: Diâmetro do colo (mm) das mudas de Schizolobium amazonicum em diferentes idades de avaliação na média dos três ambientes.

Figure 2: Stem diameter ( $\mathrm{mm}$ ) of seedlings Schizolobium amazonicum at different ages assessment on the average of three environments.

Este pequeno desenvolvimento do colo se deve inicialmente ao fato das mudas estarem plantadas em um recipiente pequeno, quando considerado que as plantas permaneceram por um longo período no viveiro.

Para o ambiente a pleno sol o fato das plantas terem ficadas expostas ao efeito de baixas temperaturas $\left(0^{\circ} \mathrm{C}\right.$ nos meses de junho e julho com ocorrência de geadas) fez com que o crescimento não só em altura mas também do colo fosse reduzido.

Já para as mudas da casa de sombra e de vegetação o crescimento do colo foi reduzido possivelmente pelo sombreamento, pois segundo Rosa et al. (2009) ocorre uma tendência à redução no crescimento diamétrico, com o aumento do sombreamento, que demonstra que o crescimento do paricá na fase juvenil não responde favoravelmente a sombreamentos intensos. Segundo Kozlowski (1962), o aumento do sombreamento diminui a fotossíntese e, consequentemente, a produção de fotoassimilados e reguladores de crescimento, causando redução no diâmetro do caule.

Ao final das avaliações, a variação do diâmetro do colo das mudas foi positiva, apesar do baixo incremento nos valores, de 5,8 para 6,6 $\mathrm{mm}$. Este aspecto é de suma importância, visto 
que, segundo Carneiro (1995), o diâmetro do colo constitui um dos melhores indicadores do padrão de qualidade de mudas. Segundo ele, as mudas devem possuir um diâmetro de colo mínimo, de acordo com a espécie e que seja compatível com sua altura, para que seu desempenho a campo corresponda às expectativas, já que o incremento inicial e sobrevivência são fortemente correlacionados com diâmetro no momento do plantio.

Para que ocorra esse crescimento em altura e diâmetro do colo, a existência de grande área foliar nas plantas é fundamental, pois está influenciará diretamente sobre o desenvolvimento da planta. Nesse estudo, podemos observar que ocorreu, ao longo do tempo, uma variação acentuada nessa variável, onde as plantas perderam parte das folhas, entretanto esta diminuição no número de folhas é inerente a alta capacidade de desrama natural da planta, que é uma característica da espécie (Figura 3).
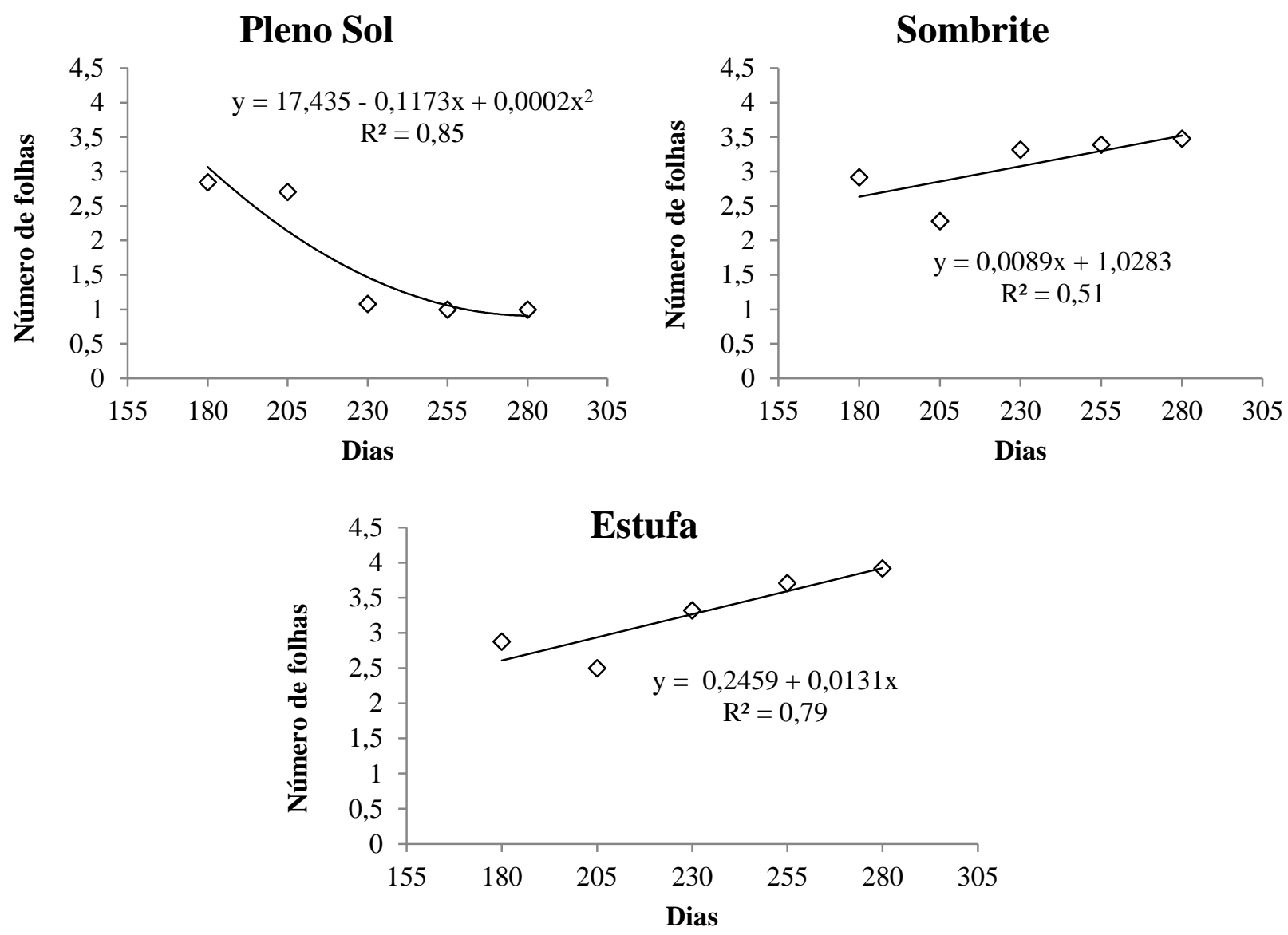

Figura 3: Número de folhas das mudas de Schizolobium amazonicum em diferentes idades de avaliação na média dos três ambientes.

Figure 3: Number of leaves of seedlings Schizolobium amazonicum at different ages assessment on the average of three environments.

Nota-se que até a segunda avaliação houve queda de folhas, fato intensificado em função da menor temperatura do período na região. Porém, a partir da terceira avaliação, novas folhas surgiram em nova estação de mais intenso crescimento, em início de primavera, favorecendo assim o desenvolvimento da planta. Caron et al. (2010), relatam que o número de pares de folhas de Schizolobium parahyba não foi influenciado pelos níveis de sombreamento e, 
sim, pelos dias após o sombreamento.

$\mathrm{O}$ desenvolvimento das mudas em relação à altura, diâmetro do colo e número de folhas foi influenciado pelas condições climáticas, mostrando que a adaptação da planta à região depende ainda de mais estudos quanto à produção de mudas e sobrevivência das mesmas em viveiro e a campo.
Ao longo do tempo de condução do experimento, a mortalidade das mudas foi aumentando (Figura 4). Esse fato ocorreu devido ao inverno e os episódios de geada nos meses de junho e julho, onde as temperaturas médias dos meses foram $13,7^{\circ} \mathrm{Ce} 14,06^{\circ} \mathrm{C}$ respectivamente, sendo a máxima dos meses $25^{\circ} \mathrm{C}$ e a mínima $0,6^{\circ} \mathrm{C}$.
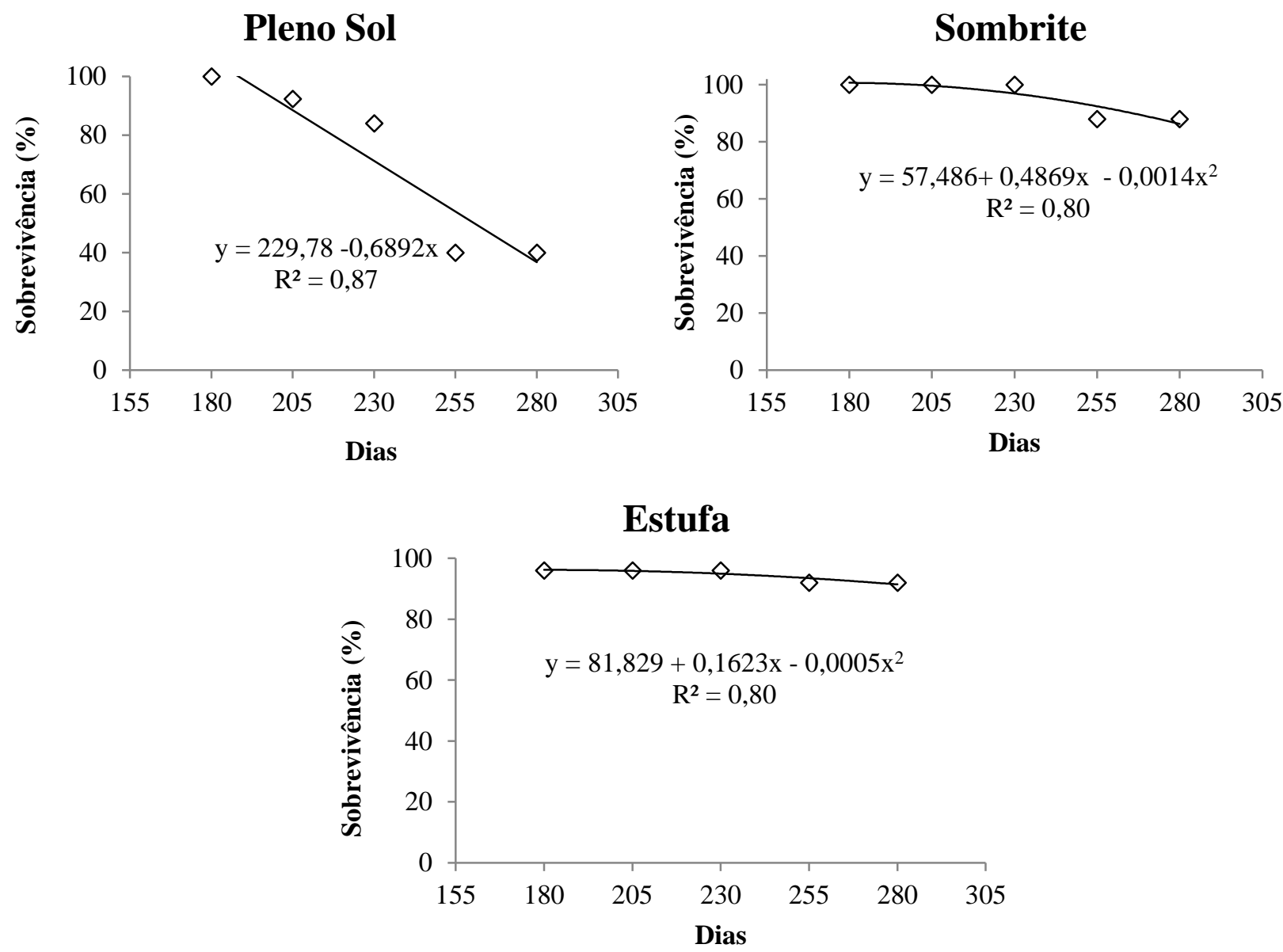

Figura 4: Sobrevivência das mudas de Schizolobium amazonicum em diferentes idades de avaliação na média dos três ambientes.

Figure 4: Survival of seedlings Schizolobium amazonicum at different ages assessment on the average of three environments.

Pode-se observar, entre a quarta e a quinta avaliação, que não houve mortalidade. Isso se deve possivelmente a temperaturas mais amenas, em função do clima primaveril do período, comparada as primeiras avaliações. Diferentemente do encontrado nesse estudo, Caron et al. (2010), ao estudarem o desenvolvimento de mudas de Schizolobium parahyba no intervalo de tempo de 20 a 60 dias após de germinação, em diferentes níveis de sombreamento a céu aberto, obtiveram $100 \%$ de sobrevivência em todos os tratamentos testados, essa grande sobrevivência também pode ser explicada pela avaliação ter ocorrido bem cedo, com apenas 60 dias, ou seja, logo após a germinação. Este fato deve-se ao estudo ter 
sido conduzido durante os meses de outubro de 2007 a janeiro de 2008, no estado do Rio Grande do Sul, o qual apresenta temperaturas superiores ao período estudado no trabalho.

As mudas apresentam maior crescimento na casa de vegetação, sendo recomendada como o melhor local para produção de mudas da espécie. A casa de sombra, por apresentar semelhança de crescimento das mudas em relação à casa de vegetação, também pode ser considerada apropriada para uso, principalmente em épocas com maiores temperaturas, excetuando-se o período de inverno no Sul do Brasil. Não é recomendada a produção de mudas da espécie em condição de céu aberto na região, pela menor resistência da espécie ao frio e os possíveis danos que poderão ser decorrentes. Mesmo assim, recomenda-se que, para a devida aclimatação das mudas antes das mesmas serem enviadas para plantio a campo, as mesmas devem passar por período em área aberta do viveiro, o qual não deve ser o inverno, mas sim, a partir do início da primavera.

Caron et al. (2010) apresenta um modelo em que mostra que o crescimento de Schizolobium parahyba deve ser mantido em estádio de produção de mudas no máximo até o $45^{\circ}$ dia após a submissão ao sombreamento, uma vez que a influência no crescimento passa a ser negativa, ou seja, as plantas iniciam processo de estiolamento, o que, no entanto não ocorreu no presente estudo até o momento da ultima avaliação.

\section{Conclusões}

Schizolobium amazonicun possui bom desenvolvimento no viveiro, principalmente sob sombreamento, alcançando cerca de $50 \mathrm{~cm}$ de altura e $7 \mathrm{~mm}$ de diâmetro do colo em 280 dias, sendo considerada uma espécie de rápido crescimento.

Em regiões com ocorrência de geadas, mesmo que não tão severas, a espécie precisa ser aclimatada na produção em viveiro e ser levada a campo após o período de inverno.

Recomenda-se que sejam realizados novos estudos visando avaliar a adaptação da espécie e suas diferentes procedências à região, tanto em viveiro como em campo, visando tornar a mesma uma nova alternativa à silvicultura da região sul do Brasil.

\section{Referências}

ALVARES, C. A. et al. Köppen's climate classification map for Brazil.MeteorologischeZeitschrift, Stuttgart, v. 22, n. 6, p. 711-728, 2013.

CARNEIRO, J. G. A. Produção e controle de qualidade de mudas florestais. Curitiba: UFPR/FUPEP; Campos: UENF, 1995. 451 p.

CARON, B. O. et al. Crescimento em viveiro de mudas de Schizolobiumparahyba (vell.) s. f. Blake. submetidas a níveis de sombreamento. Ciência Florestal, Santa Maria, v. 20, n. 4, p. 683-689, 2010.

CARVALHO, P. E. R. Paricá - Schizolobium amazonicum. Colombo: Embrapa Floresta, (Circular Técnica 142). 2007. 8p.

COSTA, D. H. M. et al. Alguns aspectos silviculturais sobre o Paricá (Schizolobium amazonicum Huber). (Série Rural 2). 1998. $23 \mathrm{p}$.

COSTA, E. C. et al. Entomologia Florestal. Santa Maria: UFSM. 2008. 240 p.

GURTH, P. Forstpflanzen und Kulturesfolgeine literaturubersich. Allg. Forest - v. Jagztg, Frankfurt, V. 140, P. 240-246, 1976.

INSTITUTO AGRONÔMICO DO PARANÁIAPAR. Sistema de Monitoramento Agroclimático do Paraná. Disponível em: www.iapar.br. Acesso em: 04 de agosto. de 2014.

KOZLOWSKI, T. T. Tree growth. New York: The Ronad Press. 1962. p. 149-170. 
MELO, R. R.; CUNHA, M. C. L. Crescimento inicial de mudas de mulungu (Erythrina velutina Wild.) sob diferentes níveis de luminosidade. Ambiência, v. 4, n. 1, p. 67-77, 2008.

PAIVA, H. N.; GOMES, J. M. Viveiros florestais. Viçosa: Universidade Federal de Viçosa. 1993. 56 p.

PECK, R. B. Informe sobre o desenvolvimento de sistemas agrossilvipastoris na Amazônia: Relatório sobre consultoria ao CPATU de 15.09.70 a 15.12.79. Belém: EMBRAPACPATU, 1979. 79 p.

ROSA, L. S. Emergência, crescimento e padrão de qualidade de mudas de Schizolobium amazonicum huber ex ducke sob diferentes níveis de sombreamento e profundidades de semeadura. Revista de ciências agrárias, n. 52, p. 87-98, 2009.

SOUZA, B. D. et al. Informátivo técnico da Rede de Sementes da Amazônia.ParicáSchizolobium amazonicum Huber exDucke. Benevides, PA, $\mathrm{N}^{\mathrm{o}}$ 13, 2005.

UCHIDA T; CAMPOS, M. A. A. Influência do sombreamento no crescimento de mudas de cumaru (Dipteryxodorata (Aubl.) Willd. Fabaceae), cultivadas em viveiro. Acta Amazônica, Manaus, v. 30, n. 1, p.107-114, 2000.

VIEIRA, F.; GOMES, S. W. F.; LIMA, J. P. C.; MELLO FILHO, J. A. Schizolobium parahyba

(Veil.) uma análise de desenvolvimento em três ambientes na fase de viveiro. Floresta e

Ambiente, Rio de Janeiro, v. 5, n. 1, p. 118-123, jan./dez. 1998. 